\title{
Trends in the Scientific Literature on Sudden Hearing Loss: A Bibliometric Study
}

\author{
F. Javier Povedano-Montero ${ }^{1,2,3}$, Francisco López-Muñoz ${ }^{2,4,5,6}$, Lorenzo Navarro-Cobos ${ }^{7}$, Virgilio López-Truchado ${ }^{8}$, Pedro Clarós ${ }^{9 *}$ \\ ${ }^{1}$ Faculty of Optics and Optometry, Complutense University of Madrid, Spain \\ ${ }^{2}$ Faculty of Health Sciences, University Camilo José Cela, Madrid, Spain \\ ${ }^{3}$ Neurology Unit, Hospital Doce de Octubre Research Institute (i+12). Madrid, Spain \\ ${ }^{4}$ Neuropsychopharmacology Unit, Hospital 12 de Octubre Research Institute (i+12),Madrid, Spain \\ ${ }^{5}$ Portucalense Institute of Neuropsychology and Cognitive and Behavioural Neurosciences (INPP), Portucalense University, Porto, Portugal \\ ${ }^{6}$ Thematic Network for Cooperative Health Research (RETICS), Addictive Disorders Network, Health Institute Carlos III, MICINN and FEDER, \\ Madrid, Spain \\ ${ }^{7}$ Tu Visión las Rosas, Madrid, Spain \\ ${ }^{8}$ Opticalia San Gabino, Madrid, Spain \\ ${ }^{9}$ Clarós Clinic, Barcelona, Spain
}

*Corresponding Author: Pedro Clarós, Clarós Clinic, Barcelona, Spain.E-mail: clinica@ clinicaclaros.com

Received Date: January 21, 2020; Accepted Date: February 12, 2020; Published Date: February17, 2020.

Citation: Povedano-Montero F. J, Francisco L Muñoz, Lorenzo N Cobos, Virgilio L Truchado, Pedro Clarós. (2020) Trends in the Scientific Literature on Sudden Hearing Loss: A Bibliometric Study. J Clinical Otorhinolaryngology, 2(1): Doi: 10.31579/ 2692-9562/002

Copyright: ( ) 2020. Pedro Clarós. This is an open-access article distributed under the terms of the Creative Commons Attribution License, which permits unrestricted use, distribution, and reproduction in any medium, provided the original author and source are credited

\begin{abstract}
Objective: To analyze the scientific publications, from a bibliometric approach, on the sudden hearing loss since the first documents appear (1966) until the year 2017.
\end{abstract}

Methods: The Scopus database was used to carry out the study, and the descriptors "sudden hearing loss", "sudden sensorineural hearing loss" and "sudden sensorial hearing loss" were used, limited to the title, keywords and summary field. The most common bibliometric indicators were applied for the selected publications.

Results: A total of 2,509 original articles were recovered between1966-2017. The growth of the publications was adapting better to a linear adjustment $(r=0.84)$. The time of duplication is 10.4 years. Bradford's core (most productive journals) formed by thirteen journals, some of the most productive are Otology and Neurotology, Acta Oto-Laryngologica and Laryngoscope, with an Impact Factor of 2.024, 2.471 and 1.116, respectively. Regarding geographical distribution, the United States, Japan and Germany present the highest production.

Conclusions: The scientific production on the sudden hearing loss follows a linear growth, without evidence that should have reached a saturation point. In this case, the postulates of the Law of growth of Price's science are not fulfilled. In addition, a high index of transience exists.

Keywords: sudden hearing loss, bibliometry, price, lotka

\section{Introduction}

Sudden hearing loss, commonly known as sudden deafness (SSNHL), is defined as a sensorineural loss of more than $30 \mathrm{dBs}$ in 3 or more consecutive frequencies, occurring in less than 72 hours [1]. The inclusion in the first 72 hours of sudden deafness allows us to distinguish another entity called rapidly progressive deafness, in which the hearing loss occurs in a period greater than 72 hours [2]. It usually occurs as a unilateral, sudden and rapidly progressive hearing loss [3].

Patients suffering from sudden deafness report that they have lost their hearing upon waking in the morning, while other patients perceive a loud explosive sound just before losing their hearing.
This pathology is considered by the otorhinolaryngologists as a true medical emergency. Approximately half of people with SSNHL can recover part or all of their hearing spontaneously or within one or two weeks from the onset of symptoms (65\%) [4], although the lower the hearing loss, the better the prognosis, Even so, delaying the diagnosis and treatment can decrease the recovery of the hearing [5]. Receiving treatment in a timely manner greatly increases the chances of recovering at least part of the hearing [6-7].

Some studies show that SSNHL can affect people of any age, but it is more frequent in adults between 45 and 55 years, with a higher prevalence in women, being very rare that it occurs in children. It has been described that $6.6 \%$ of patients with SSNHL were under 18 years of age [8], 3.5\% 
under 14 years [8] and only $1.2 \%$ under 9 years [10]. The global prevalence of this disorder ranges from $5 / 20$ patients per 100,000 inhabitants (data for the United States) (1), and there may be 15 million affected worldwide [11].

The etiological diagnosis of SSNHL is usually controversial [12] and only around $10 \%$ of patients diagnosed provide a justifiable cause. Some of the most frequent disorders are infections, labyrinthine hemorrhage, and disorders of the microcirculation, autoimmune diseases, neurological disorders (multiple sclerosis), Menière's disease or idiopathic causes [13, 16]. However, the viral etiology is increasingly accepted by many authors. The infection by herpes virus type I or II, varicella and zoster may be behind its etiology [17]. For this reason it is advisable to associate antivirals with standard treatments.

Unfortunately in most cases (between 70 and 90\%), and despite an exhaustive search of the causes, none are found [18].

If there are symptoms of SSNHL, such as full ear, dizziness, ringing in the ears or tinnitus, it should be ruled out that the loss is conductive, performing otoscopy to check that there is no obstruction due to fluid or wax, pure tone audiometry and tympanometry. If sudden deafness is diagnosed, other tests will be done to try to determine the cause, such as blood tests, diagnostic imaging tests (magnetic resonance imaging) and balance tests (dynamic posturography and videonystagmography). The otoacoustic emissions as well as vestibular potentials (VEMPS) can also provide us with additional information.

There is no standard treatment protocol, but the most accepted therapeutic regimen is the use of corticosteroids $[19,21]$. The mechanism of action in the inner ear is not clear, but a higher perilymphatic concentration of corticosteroids is associated with greater recovery of hearing [22]. The treatment has to be focused on increase the irrigation of the inner ear to reduce the inflammation. It has been demonstrated that intratympanic steroid injections are as effective as oral [23, 24], and is an option for people who cannot take oral steroids, or who do not obtain the expected results with oral treatment.

Corticosteroids should be used as soon as possible, to obtain the best results [6,7], even before obtaining all the tests, because if it is delayed, the chances of reversing the hearing loss decrease. The SSNHL constitutes a real therapeutic urgency and everything that delays it will be to the detriment of the result.

Another treatment that has proven effective is hyperbaric oxygen therapy when it starts in the first weeks after the symptoms [25, 26]. It is thought that SSNHL produces hypoxia of the cochlear zone and this treatment would improve the oxygenation of the external hair cells [27, 28]. However, the hyperbaric chamber is only valid if it is used at 48 or 72 hours, maximum after five days. The experience with it is accepted by most authors, but in these conditions.

The work we have done is a bibliometric type study. Bibliometry can be defined as the science that studies the nature and course of a discipline (as long as it gives rise to publications), through the computation and analysis of several facets of written communication [29]. Bibliometric analysis includes the collection, processing and management of quantitative bibliographic data from scientific publications [30].

The term bibliometry refers to a group of bibliographic searches and scientific information that allows us to analyze the production and dispersion of a specific topic in a statistically quantitative way [31].
Thanks to the use of statistics, bibliometric indicators allows us to measure the amount of scientific publications made by researchers, and a series of characteristics of them, with which we can analyze scientific literature [32].

The parameters that are used in the evaluation process of any activity can be defined as "indicators". Both production and dispersion are indicators of impact [33]. The production allows us to know if a specific topic is booming or not and which authors write more about the topic and the dispersion shows which magazines publish these articles. The impact factor (IF) is used to measure the visibility and usefulness of the sources, and allows to determine the interest that documents have in terms of their greater or lesser use by different users. The IF, devised by Eugene Garfield [34], is published annually as part of the Journal Citation Report.

This type of bibliometric studies are of great help to know the social and scientific importance of a discipline or a specific field. Our group has studied, with a bibliometric approach, the evolution of scientific literature in different areas of biomedicine [35, 44].

\section{Material and Method}

the database used in this study, Scopus, is the largest summary and citation database that evaluates scientific literature equally (scientific journals, books and conferences). It covers almost 22,000 titles from more than 5,000 publishers, of which 21,500 are scientific, technical, medical and social science journals (this includes arts and humanities). Scopus is the most complete and easy to use database in the biomedical field in comparison with any other tool used in scientific literature research, it is considered the largest database in the world, and is commonly used by researchers to perform bibliometric analysis $[45,46]$.

Through the use of remote downloading techniques, documents published since 1966 (year in which the first records appear) have been retrieved up to 2017. The search has been limited in the summary field, title and keywords, using the specific descriptors: "sudden hearing loss", "sudden sensorial hearing loss" and "sudden sensorineural hearing loss".

In this study, the most common bibliometric indicators were used: Price Index, doubling time, annual growth rate, Price transience index, Lotka Law and the Bradford Zones.

Among the production indicators we have applied the Price law [31]. This law is the most used indicator in the analysis of the productivity of a specific discipline or a particular country, to reflect a fundamental aspect of scientific production, which is its growth. To assess if the scientific production in the SSNHL follows the Price law, we have created a linear trend curve that is expressed in the following way $\mathrm{y}=0.2111 \mathrm{x}-414.49$ and another for the exponential trend line according to the equation $\mathrm{y}=$ $2 \mathrm{E}-75 \mathrm{e}^{0,086 \mathrm{x}}$.

Related to the growth, is the time of duplication and the annual growth rate. The first is the amount of time required by the subject of study to double his production. The form of growth was studied from the equation of Egghe and Ravichandra [47], this function is represented mathematically as:

$$
C(t)=\operatorname{cgt}
$$

Where $\mathrm{C}(\mathrm{t})$ is the total number of documents produced at time $\mathrm{t}$; $\mathrm{c}$ and $\mathrm{g}$ represent estimated constants of the observed data, taking into account that $c>0, g>1$, and $t \geq 0$; $t$ is the number of chronological years studied in 
the research period $(t=0,1,2, \ldots, n)$. The model not only provides an average rate of growth, but also offers a rate of duplication.

Among the bibliometric indicators of dispersion, we have applied the Bradford zones. Bradford evidenced the concentration in a small number of journals the majority percentage of the pertinent bibliography in a subject, which implies a rapid fall in the performance of expanding the search for references outside this nucleus [48].

To know the influence of publications, the Impact Factor (IF) is used. This indicator is calculated taking into account the times a journal has been cited in the Science Citation Index database in the last two years and the total number of articles published in this journal in those same years. The list of scientific journals of the Journal Citation Report, divided into different areas, attributes to each one an IF and establishes its prestige range [49].

Finally, the Lokta indicator was used, which enunciated the law on the distribution of authors based on the number of articles published [50], also known as the "inverse quadratic of scientific production". It studies the publication volume of the authors and states that the number that publishes few works is greater than the amount published by many. This law establishes that in the entire scientific community, the number (A) of authors who have published a number (n) of works, in the course of a period of several years of activity, i.e. A (n) authors, is equal to the number of those who have published a single work, A (1), in the same period of time, divided by the square of $n$. In mathematical terms the original law is expressed by the formula:

$$
A(n)=\frac{A(1)}{n^{2}}
$$

It is also interesting to know the number of authors with only one work. It is what is known as a transience or price index. Its calculation is given as the percentage of the quotient of the authors with a single job among the total. Mathematically it would be expressed:

$$
\mathrm{Tl}=\frac{\text { Authors with a single job }}{\text { total authors }} \times 100
$$

\section{Results}

Through the search criteria used, 2,509 records (articles, magazines, letters to the director, etc.) have been recovered, during the period spanning from 1966, the year of the first registrations, until 2017. The chronological distribution is illustrated in the Fig. 1.

Figure 1. Chronological evolution of the scientific production on the SSHNL. Linear adjustment (a): $y=2.8685 x-5664.4\left(r^{2}=0.83\right)$

Exponential adjustment $(b): y=8 E-83 e^{0.0965 \times}\left(r^{2}=0.78\right)$

\section{№ of Document}

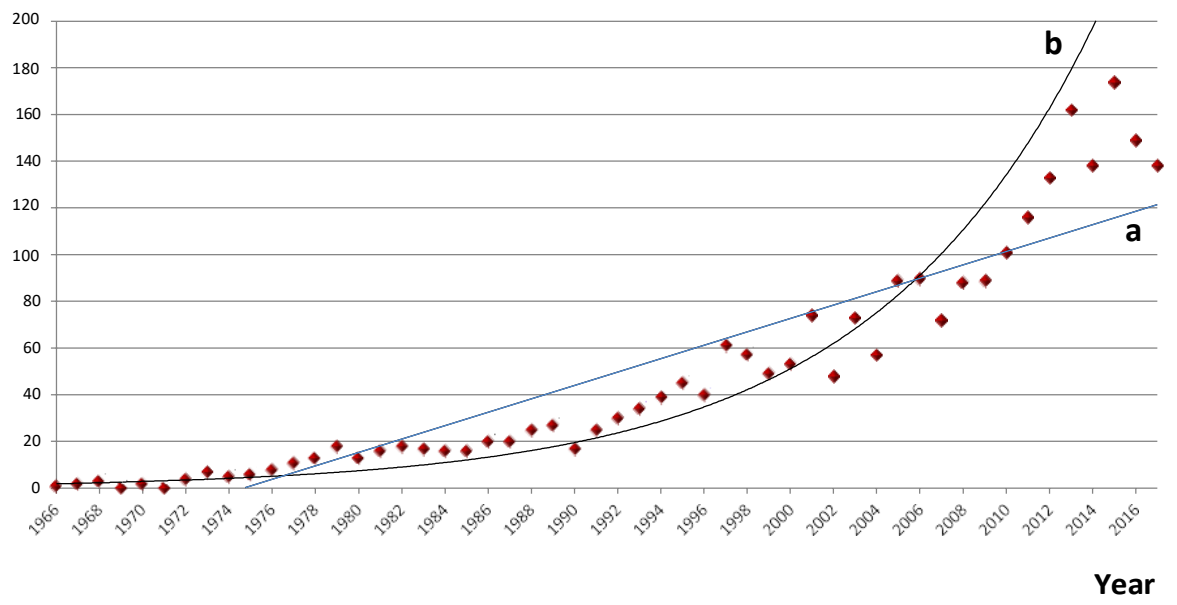

To determine whether growth follows Price's exponential growth law, we have ordered the data in a linear fashion according to the formula $\mathrm{y}=$ $2.8685 \mathrm{x}-5664.4$ and another that fits the exponential curve according to the formula $y=8 \mathrm{E}-83 \mathrm{e}^{0.0965 \mathrm{x}}$. In this way, the value of the coefficient of determination is greater in the linear function, with a value of 0.83 , which shows the power of representation compared to the exponential which has a value of 0.78 . With these data we can conclude that the analyzed repertoire is better adapted to a linear adjustment than to an exponential one and that the postulates of the Price Law, in this case, are not fulfilled.

Table 1 shows the parameters and values obtained from the application of the exponential model by the non-linear regression method. 


\begin{tabular}{|c|c|c|c|c|}
\hline \multirow[b]{2}{*}{ Parameter } & \multirow[b]{2}{*}{ Estimate } & \multirow[b]{2}{*}{ Std. error } & \multicolumn{2}{|c|}{ 95\% Confidence Interval } \\
\hline & & & Lower Bound & Upper Bound \\
\hline $\mathrm{c}$ & 5.665 & 0.727 & 4.204 & 7.126 \\
\hline $\mathrm{g}$ & 1.069 & 0.003 & 1.063 & 1.075 \\
\hline
\end{tabular}

Table 1. Values of the parameters obtained with the exponential model.

The value of $\mathrm{c}$ is 5.665 and that of $\mathrm{g}$ 1.069. With these values the Egghe and Ravichandra Rao equation can be established, and thus predict the growth of the published literature on SSNHL:

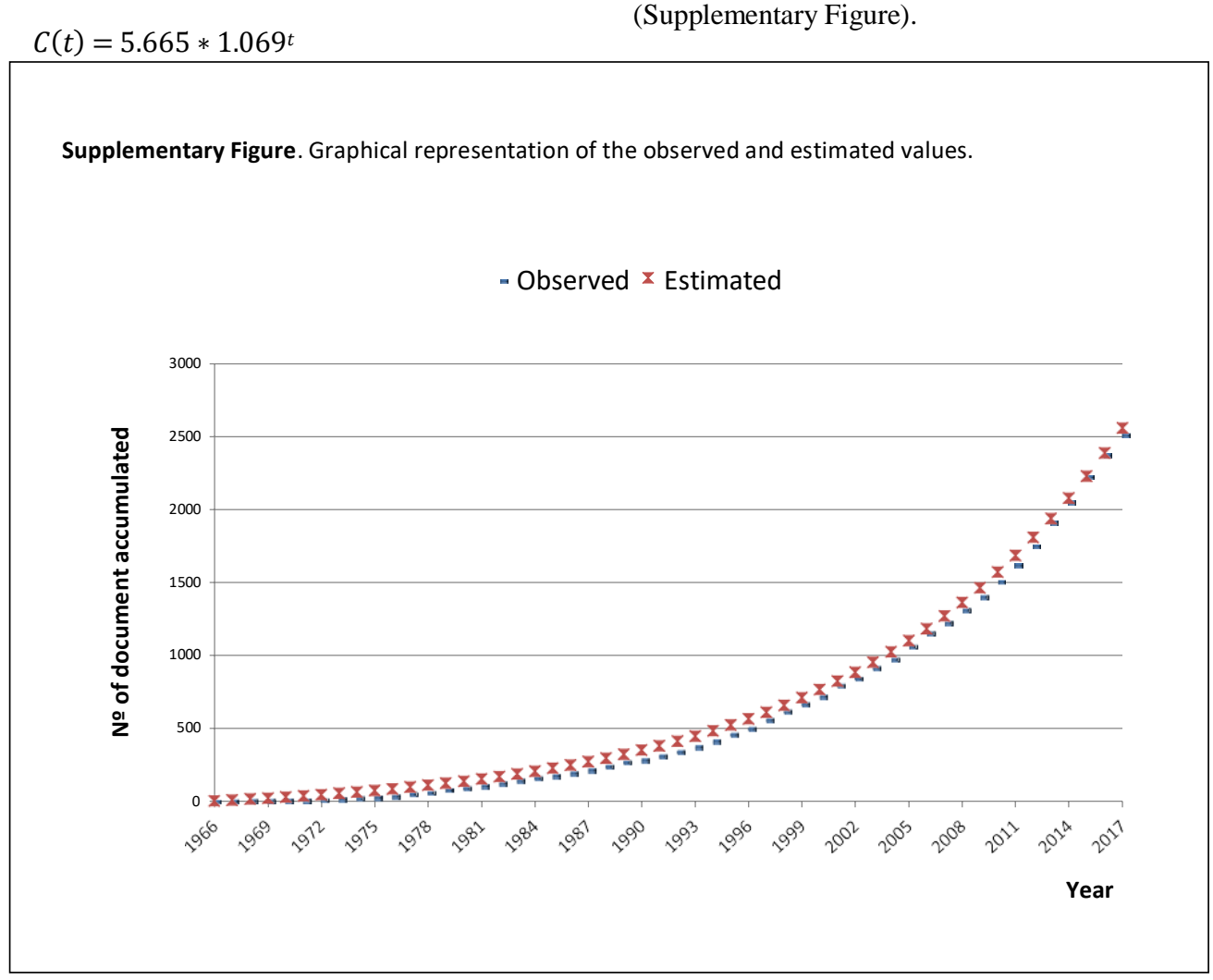

As illustrated in Figure 2, the period between the years 2017-2013 is the one that contains the largest number of documents with more than $30 \%$ of the total of them.

The most productive countries are the US, Japan and Germany. These 3 countries account for more than $40 \%$ of total production (Fig. 3).
From this method it is inferred that the literature on SSNHL grows at a rate of $6.9 \%$ per year with a production that doubles its size every 10.4 years. We have obtained that the model is explained at $95.6 \%$ (Supplementary Figure).

Among the most productive institutions, we highlight the LudwigMaximilians-Universitat Munchen, Harvard Medical School and Taipei Medical University, the university being the type of institution that provides the most documents (Fig. 3). 


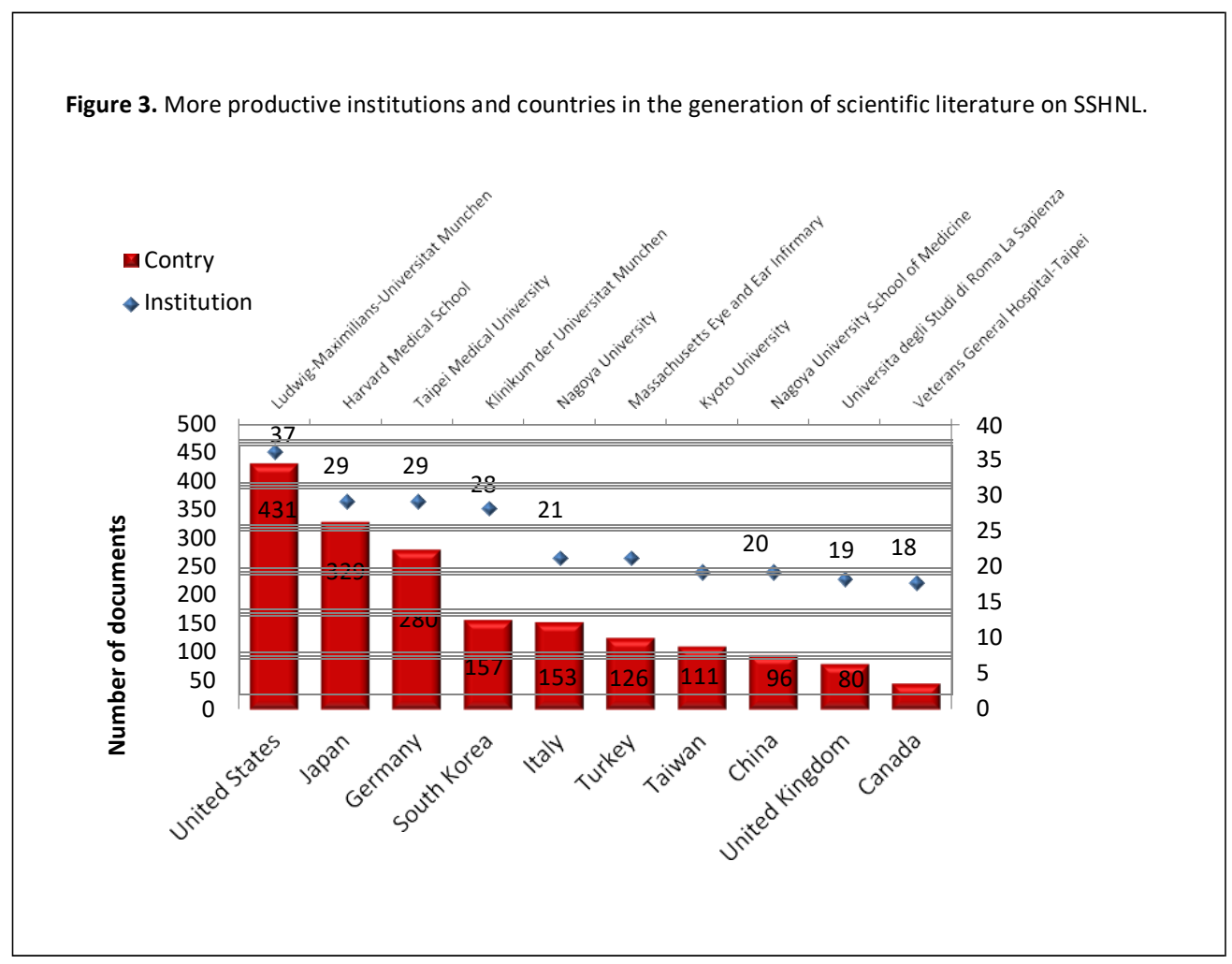

As regards the scientific journals in which the articles on sudden deafness have been published, the Bradford model was applied. The average number of articles per Bradford area was 627. Table 2A shows Bradford's zoning of the articles that are part of this study.

\begin{tabular}{|c|c|c|c|c|c|}
\hline & $\mathbf{N}^{\mathbf{0}}$ of Journals & \% Journals & $\mathbf{N}^{\mathbf{0}}$ of Articles & \% Articles & $\begin{array}{l}\text { Bradford } \\
\text { Multiplier }\end{array}$ \\
\hline Core & 7 & 1.16 & 633 & 25.23 & 3.28 \\
\hline Zone 1 & 23 & 3.80 & 632 & 25.19 & 5.13 \\
\hline Zone 2 & 118 & 19.47 & 676 & 26.94 & 3.88 \\
\hline Zone 3 & 458 & 75.58 & 568 & 22.64 & 4.10 \\
\hline TOTAL & 606 & 100.00 & 2509 & 100.00 & \\
\hline
\end{tabular}

Table 2A. Distribution of journals in the Bradford Zones.

The core is composed of 7 journals, 1.16 of them, with more than $25 \%$ of the articles published. Table $2 \mathrm{~B}$ shows the IF data (impact factor) of the most productive journals, according to data from JCR 2017, as well as other data of interest. 


\begin{tabular}{|c|c|c|c|c|c|}
\hline Source & $\begin{array}{c}\mathbf{N}^{\mathbf{0}} \text { of } \\
\text { Documents }\end{array}$ & PI* $^{*}$ & $\begin{array}{c}\text { Impact } \\
\text { Factor } \\
\text { JCR 2017 }\end{array}$ & Country of origin & $\begin{array}{c}\text { Abbreviated journal } \\
\text { title }\end{array}$ \\
\hline Otology and Neurotology & 124 & 4.94 & 2.024 & United States & Otol Neurotol \\
\hline Acta Oto-Laryngologica & 118 & 4.70 & 1.116 & Uniteted Kingdom & Acta Oto-Laryngol \\
\hline $\begin{array}{c}\text { Luropean Archives of Oto-Rhino- } \\
\text { Laryngology }\end{array}$ & 112 & 4.46 & 2.471 & United States & Laryngoscope \\
\hline $\begin{array}{c}\text { Journal of Laryngology and } \\
\text { Otology }\end{array}$ & 76 & 3.03 & 0.884 & Uniteted Kingdom & J Laryngol Otol. \\
\hline Hals-Nasen-Ohrenheilkunde & 58 & 2.31 & 0.723 & Germany & HNO \\
\hline $\begin{array}{c}\text { Otolaryngology - Head and Neck } \\
\text { Surgery }\end{array}$ & 54 & 2.15 & 2.444 & United States & Otolaryng Head Neck \\
\hline
\end{tabular}

\section{*IP: Participation Index}

$$
\text { Table 2B. Journals with highest number of publications on SSHNL. }
$$

Table 3A shows the distribution of authors according to Lotka's Law. As can be seen, this distribution is strongly concentrated in small producers, with a transience index (occasional authors) of close to $80 \%$, and the presence of only $0.70 \%$ as large producers (authors with 10 or more articles). The total number of authors is 7,028, which represents for the 2,509 documents recovered a co-authorship index of 2.80.

\begin{tabular}{|l|c|c|c|c|}
\hline & $\begin{array}{c}\mathrm{PI} \geq 1 \\
(10 \text { or more articles })\end{array}$ & $\begin{array}{c}0<\mathrm{PI}<1 \\
(2-9 \text { articles })\end{array}$ & PI=0 (1 article $)$ & Total \\
\hline $\mathrm{N}^{\mathrm{o}}$ Authors & 49 & 1580 & 5399 & 7028 \\
\hline$\%$ Authors & 0.70 & 22.48 & 76.82 & 100.00 \\
\hline
\end{tabular}

If we continue with the analysis of the authors, we have been able to highlight, as illustrated in Table 3B, that 6 authors, among the 10 most productive, are Japanese.

\begin{tabular}{|l|l|l|l|l|l|}
\hline Author & $\begin{array}{l}\mathrm{N}^{\mathrm{o}} \text { of } \\
\text { documents }\end{array}$ & IP* & H index & Affiliation & Country \\
\hline Nakashima T. & 36 & 1.43 & 37 & $\begin{array}{l}\text { Ichinomiya Medical Treatment and Habilitation } \\
\text { Center }\end{array}$ & Japan \\
\hline Suzuki H. & 21 & 0.84 & 16 & $\begin{array}{l}\text { University of Occupational and Environmental } \\
\text { Health }\end{array}$ & Japan \\
\hline Ogawa K. & 19 & 0.76 & 27 & Keio University School of Medicine & Japan \\
\hline Sone M. & 19 & 0.76 & 27 & Nagoya University School of Medicine & Japan \\
\hline Lin H.-C. & 18 & 0.72 & 39 & Taipei Medical University & Taiwan \\
\hline Suckfüll M. & 18 & 0.72 & 14 & Martha und Maria Helfen Krankenhaus & Germany \\
\hline Ito J. & 16 & 0.64 & 41 & Shiga Medical Center Research Institute. & Japan \\
\hline Teranishi M. & 16 & 0.64 & 26 & Nagoya University School of Medicine & Japan \\
\hline Wang H. & 16 & 0.64 & 14 & South China University of Technology & China \\
\hline Weng S.-F. & 16 & 0.64 & 17 & Chi Mei Medical Center & Taiwan \\
\hline
\end{tabular}

*IP: Participation Index

Table 3B. Most productive authors.

Another interesting fact is the number of signatures of the articles, a fact that indicates the degree of collaboration of the authors. In this study we have verified that the most common co-authorship index is of 3 firms and that the article with the most collaboration has 31 signatures (Supplementary Table). 


\begin{tabular}{|c|c|c|}
\hline Signing authors & $\mathrm{N}^{0}$ Documents & Documents (\%) \\
\hline 31 & 3 & 0.12 \\
\hline 30 & 1 & 0.04 \\
\hline 26 & 1 & 0.04 \\
\hline 22 & 2 & 0.08 \\
\hline 21 & 1 & 0.04 \\
\hline 19 & 2 & 0.08 \\
\hline 18 & 2 & 0.08 \\
\hline 17 & 2 & 0.08 \\
\hline 16 & 2 & 0.08 \\
\hline 15 & 8 & 0.32 \\
\hline 14 & 3 & 0.12 \\
\hline 13 & 10 & 0.40 \\
\hline 12 & 10 & 0.40 \\
\hline 11 & 17 & 0.68 \\
\hline 10 & 25 & 1.00 \\
\hline 9 & 39 & 1.55 \\
\hline 8 & 92 & 3.67 \\
\hline 7 & 153 & 6.10 \\
\hline 6 & 268 & 10.68 \\
\hline 5 & 351 & 13.99 \\
\hline 4 & 407 & 16.22 \\
\hline 3 & 438 & 17.46 \\
\hline 2 & 385 & 15.34 \\
\hline 1 & 287 & 11.44 \\
\hline
\end{tabular}

\section{Discussion}

Bibliometric studies have become essential tools for evaluating scientific activity, allowing an overview of the growth, size and distribution of scientific literature associated with a particular discipline $[33,51,53]$.

However, despite the benefits of this sociometric approach, its limitations must also be taken into account. For example, bibliometric studies do not take into account neither the quality of the publications nor the fact that the results of the scientific activity are only measured by publications. The aspects that are not considered include teaching, applied research or scientific dissemination $[54,55]$. However, these studies are an effective complement to the opinions and judgments of experts in each field, and are useful and objective tools to evaluate the results of scientific activity, offering a more realistic view of the general situation and an indication of trends, as well as a prediction of how the subject of analysis could evolve [56].

The results obtained, from this bibliometric analysis, allow us to understand the development of the scientific literature in recent decades on sudden deafness. In this regard, it should be noted, as shown in Fig. 1, that the number of scientific publications has experienced a linear growth, in the last 52 years, and that, therefore, Price's Law of Growth of Science is not fulfilled, theory of the expansion of scientific literature [36]. We can highlight the years 2015, 2013 and 2016 as the most productive (Fig. 1) and the period 2017-2013 which contains the largest number of publications (Fig. 2).

Supplementary Table. Signing authors per document.

Figure 2. Distribution the scientific production on SSHNL for five year periods.

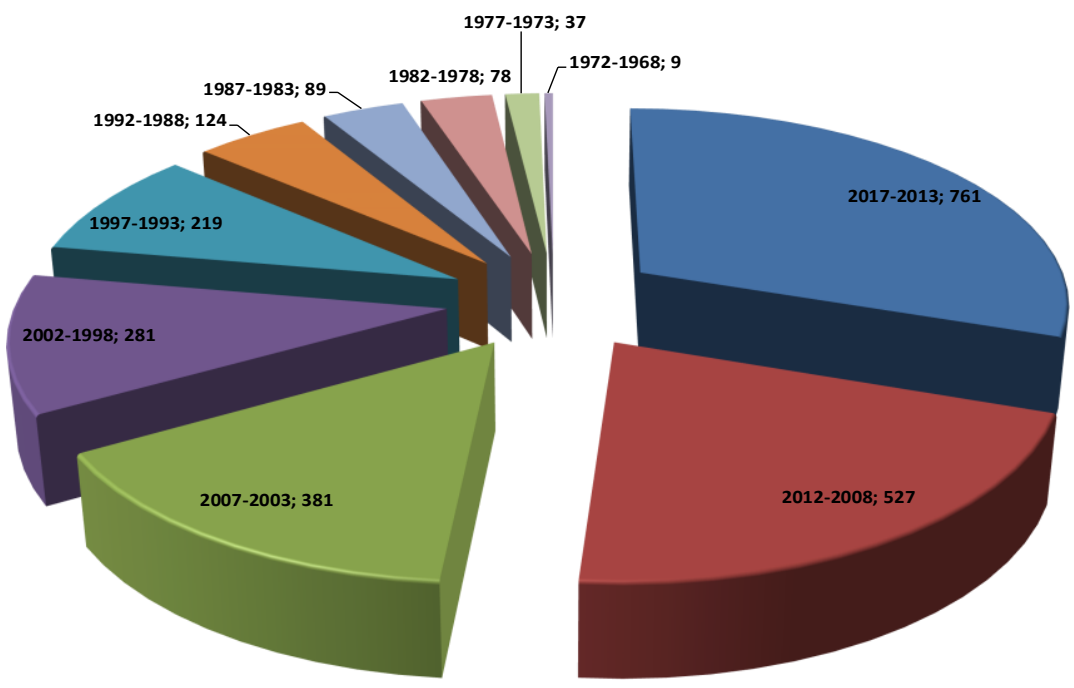


The increase in documents is due both to studies that attempt to analyze the prevalence of this pathology [1, 8, and 11] and studies about its treatment. In 2013, we found a study on the incidence of sudden deafness in the United States [57], where they sought to link SSNHL with age, ethnicity, gender..., demonstrating a relationship with age and an increase in patients over the years, both in young people and in adults. In 2017 these data are updated [58], showing a slightly higher prevalence in women, where the male-female ratio stands at 1:1.35. Similarly, it was observed, in relation to age, that it is higher in people over 55 years of age and finally, a relationship with climate was found, that is, in autumn (when the temperature is colder) there are more cases of sudden deafness.

Due to the increase in patients that is occurring annually, the need arises to investigate to find effective treatments. In this sense, in recent years there has been an increase in the number of publications dealing with corticosteroids [59], intratympanic injections [60] and hyperbaric oxygen therapy $[25,26]$. These studies demonstrate the efficacy against sudden deafness, either in combination therapy [61] or individually [62-64], reaching the conclusion that early and successful treatment obtains very favorable results $[6,7]$.
The most productive countries on sudden deafness are the USA, Japan and Germany. The United States being the country with the most documents, however, one institution in Germany is the most productive, Ludwig-Maximilians-Universitat Munchen. Among the ten most productive institutions, we only find two from the US, Harvard Medical School and Massachusetts Eye and Ear Infirmary.

The transience index is quite high, with a value of $84 \%$ which indicates that most authors have written on the subject occasionally. The medium producers make up $15.86 \%$ while the great authors only represent $0.07 \%$.

In this sense we find that 10 authors of the 7,028, who make up the study, are responsible for a high percentage of these works, more than $7 \%$. Among these authors we find five Japanese, T. Nakashima, H. Suzuki, K. Ogawa, M. Sone, J. Ito and M. Teranishi. The H index is one of the bibliometric indicators that are being used most to estimate the success of work of a researcher. This indicator estimates the number of important works published by an author. Thus, we have seen, as reflected in Table 4, that the 10 authors have an index $\mathrm{H}$ greater than 10 , and we found 2 authors with an index of 39 and 41 (H.-C. Lin and J. Ito, respectively).

\begin{tabular}{|l|c|c|c|c|}
\hline & PI $\geq 1$ & PI=0 (1 article) & Total \\
\hline No Authors & 49 & 1580 articles $)$ & 5399 & 7028 \\
\hline \% Authors & 0.70 & 22.48 & 76.82 & 100.00 \\
\hline
\end{tabular}

The interest of such important researchers demonstrates the relevance of the subject of study. Another fact, which reinforces this argument, is that the time of duplication of the scientific literature is only 10.4 years.

To analyze the quality of the articles, the impact and excellence indicators of the publications on the subject in question were used. The fact that prestigious journals such as Laryngoscope $(\mathrm{IF}=2.471)$, Otolaryngology - Head and Neck Surgery (IF = 2.440) or Otology and Neurotology (IF = 2.024) will publish articles on SSNHL is an important fact that indicates the relevance (both clinical and social) that this pathology has acquired in recent years.

Finally, and to conclude, it can be affirmed that, despite the limitations of bibliometric studies, and thanks to the design of this study, we have been able to offer an image of the representativeness and evolution of sudden deafness, observing quality parameters and diffusion more commonly used at international level. Research in this field will probably continue to grow, due to the need presented by an aging population.

\section{Conclusions}

By way of conclusion, it can be asserted that, despite the limitations characteristic of bibliometric studies, and thanks to the design of this study, we have been able to offer a picture of the representativeness and evolution of international research on SSHNL. Research in this field will possibly continue to grow in the coming years due to the continuous ageing of populations and associated pathologies.

\section{Conflicting interests}

The authors declare that there is no conflict of interest.

\section{Funding}

This research received no grant from any funding agency in the public, commercial, or not-for-profit sectors.

\section{Contributions}

FJP-M and FL-M designed the study and wrote the protocol. FJP-M, FLM, LN-C and VL-T managed the literature searches. FJP-M and FL-M made the bibliometric analyses. FJP-M, FL-M and PC wrote the first draft of the manuscript. All authors contributed to and have approved the final manuscript.

\section{ORCID}

F.J. Povedano-Montero: 0000-0001-6715-1047

F. López-Muñoz: 0000-0002-5188-6038

P. Clarós: 0000-0002-7567-0370

\section{References}

1. Stachler RJ, Chandrasekhar SS, Archer SM, et al. (2012). Clinical practice guideline: Sudden hearing loss. Otolaryngol - Head and Neck Surgery. 146(SUPPL.3):S1-S35.

2. Terayama Y, Ishibe Y, Matsushima J. (1988). Rapidly progressive sensorineural hearing loss (rapid deafness). Acta Otolaryngol Suppl, 456:43-48. 
3. Kallinen J, Laurikainen E, Laippala P, Grenman R. Sudden deafness: (1997). a comparison of anticoagulant therapy and carbogen inhalation therapy. Ann Otol Rhinol Laryngol, 106(1):22-26.

4. Hughes GB, Freedman MA, Haberkamp TJ, Guay ME. (1996). Sudden sensorineural hearing loss. Otolaryngol Clin North Am, 29(3):393-405.

5. Pecorari G, Riva G, Bruno G, Naqe N, Nardo M, Albera A, Albera R. (2020). Recurrences in Sudden Sensorineural Hearing Loss: A Long-Term Observational Study. Am J Audiol. doi: 10.1044/2019_AJA-19-00061.

6. Ganesan P, Kothandaraman PP, Swapna S, Manchaiah V. (2017). A Retrospective Study of the Clinical Characteristics and Posttreatment Hearing Outcome in Idiopathic Sudden Sensorineural Hearing Loss. Audiol Res, 7(1):168.

7. Amarillo E, Hernando M, Eisenberg G, Granda M, Plaza G. (2018). Efficacy of intratympanic corticosteroid as a salvage treatment in idiopathic sudden sensorineural hearing loss. Acta Otorrinolaringol Esp.pii: S0001-6519(18)30120-1. doi: 10.1016/j.otorri.2018.04.009.

8. Chung JH, Cho SH, Jeong JH, Park CW, Lee SH. (2015). Multivariate analysis of prognostic factors for idiopathic sudden sensorineural hearing loss in children. Laryngoscope, 125(9):2209-2215.

9. Jecmenica J, Bajec-Opancina A. (2014). Sudden hearing loss in children. Clin Pediatr (Phila), 53(9):874-878.

10. Na SY, Kim MG, Hong SM, Chung JH, Kang HM, Yeo SG. (2014). Comparison of sudden deafness in adults and children. Clin Exp Otorhinolaryngol, 7(3):165-169.

11. Vakkalanka S, Ey E, Goldenberg RA. (2000). Inner ear hemorrhage and sudden sensorineural hearing loss. Am. J. Otolaryngol, 21(5):764-765.

12. Herrero J, González F, Pimilla M. (2002). Cochlear hemorrhage. An exceptional cause of sudden sensorineural mearing loss. Acta Otorrinolaringol, 53:263-368.

13. Lee HS, Lee YJ, Kang BS, Lee BD, Lee JS. (2014). A clinical analysis of sudden sensorineural hearing loss cases. Korean $\mathbf{J}$ Audiol, 18(2):69-75.

14. Lu YY, Jin Z, Tong BS, Yang JM, Liu YH, Duan M. (2008). A clinical study of microcirculatory disturbance in Chinese patients with sudden deafness. Acta Otolaryngol, 128(11):1168-1172.

15. Kuhn M, Heman-Ackah SE, Shaikh JA, Roehm PC. (2011). Sudden sensorineural hearing loss: a review of diagnosis, treatment, and prognosis. Trends Amplif, 15(3):91-105.

16. Salomone R, Abu TAA, Chaves AG, Bocalini MCC, de Oliveira Vicente A, Riskalla PE. (2008). Sudden hearing loss caused by labyrinthine hemorrhage. Braz J Otorhinolaryngol, 74(5):776779.

17. Clarós P, Claros A. Surdité brusque. (2017). place des antiviraux en complément à la corticothérapie. Rev Laryngol Otol Rhinol, 138(1):1-5.

18. Zarandy M, Rutka J. (2010). Diseases of the inner ear. Berlin Heidelberg: Springer Verlag, 9-17.

19.
Wilson WR, Byl FM, Laird N. (1980). The efficacy of steroids in the treatment of idiopathic sudden hearing loss. A double-blind clinical study. Arch Otolaryngol, 106(12):772-776.

20. Rauch SD. (2008). Clinical practice. Idiopathic sudden sensorineural hearing loss. N Engl J Med, 359(8):833-840.

21. Marx M, Younes E, Chandrasekhar SS, Ito J, Plontke S, O'Leary S, Sterkers O. (2018). International consensus (ICON) on treatment of sudden sensorineural hearing loss. Eur Ann Otorhinolaryngol Head Neck Dis, 135(1S):S23-S28.

22. Ahn JH, Han MW, Kim JH, Chung JW, Yoon TH. (2008). Therapeutic effectiveness over time of intratympanic dexamethasone as salvage treatment of sudden deafness. Acta Otolaryngol, 128(2):128-131.

23. Nakashima T, Teranishi M, Yoshida T. (2009). In reference to Randomized, double blind, placebo controlled trial on the safety and efficacy of continuous intratympanic dexamethasone delivered via a round window catheter for severe to profound sudden idiopathic sensorineural hearing loss after failure of systemic therapy. Laryngoscope, 119(12):2480; author reply 2481-2482.

24. Plontke SK, Lowenheim H, Mertens J, et al. (2009). Randomized, double blind, placebo controlled trial on the safety and efficacy of continuous intratympanic dexamethasone delivered via a round window catheter for severe to profound sudden idiopathic sensorineural hearing loss after failure of systemic therapy. Laryngoscope, 119(2):359-369.

25. Karatop-Cesur I, Uzun G, Ozgok-Kangal K, Mutluoglu M, Yildiz S. (2016). Early treatment response predicts outcome in patients with idiopathic sudden sensorineural hearing loss treated with hyperbaric oxygen therapy. Undersea Hyperb Med, 43(7):781786.

26. Hara S, Kusunoki T, Honma H, Kidokoro Y, Ikeda K. (2019). Efficacy of the additional effect of hyperbaric oxygen therapy in combination of systemic steroid and prostaglandin E (1) for idiopathic sudden sensorineural hearing loss. Am J Otolaryngol, 102363.

27. Hesse G. (2016). Inner Ear Hearing Loss Part II: Sudden Sensorineural Hearing Loss, Therapeutic Options. Laryngorhinootologie, 95(7):461-469.

28. Ergun Tasdoven G, Derin AT, Yaprak N, Ozcaglar HU. (2017). The place of hyperbaric oxygen therapy and ozone therapy in sudden hearing loss. Braz J Otorhinolaryngol, 83(4):457-463.

29. Pritchard A. (1969). Statistical bibliograhy or bibliometrics? J Doc, 4(25):348-369.

30. Moed HF, Burger WJM, Frankfort JG, Van Raan AFJ. (1985). A comparative study of bibliometric past performance analysis and judgement. Scienciometrics, 8(3-4):149-159.

31. Price DJ. (1963). Littel science, big science. New York: Columbia University Press.

32. López Piñero JM. (1972). El análisis estadístico y sociométrico de la literatura científica. Valencia: Centro de Documentación e Informática Medica, Facultad de Medicina. 
33. Bordons M, Zulueta MA. (1999). Evaluación de la actividad científica a través de indicadores bibliometricos. Rev Esp Cardiol, 52(10):790-800.

34. Garfield E. (1955). Citation Indexes for Science. A new dimension in documentation through association of ideas. Science, 122(13159):108-111.

35. White HD, McCain KW. (1989). Bibliometric. Ann Rev Inf Sci Technol, 24:119-186.

36. López-Muñoz F, Rubio G. (1995). La producción científica española en psiquiatría: estudio bibliométrico de las publicaciones de circulación internacional durante el periodo 1980-1993. An Psiquiatr, 11:68-75.

37. López-Muñoz F, Marín F, Boya J. (1996). Evaluación bibliométrica de la producción científica española en Neurociencia. Análisis de las publicaciones de difusión internacional durante el periodo 1984-1993. Rev Neurologia, 24(128):417-426.

38. López-Muñoz F, Álamo C, Rubio G, García-García P, Martin Ageda B, Cuenca E. (2003). Bibliometric analysis of biomedical publications on SSRIs during the period 1980-2000. Depress Anxiety, 18(2):95-103.

39. López-Muñoz F, García-García P, Saiz-Ruiz J, et al. (2008). A bibliometric study of the use of the classification and diagnostic systems in psychiatry over the last 25 years. Psychopathology, 41(4):214-225.

40. Redondo M, León L, Povedano Montero F, Abasolo L, PérezNieto M, López-Muñoz F. (2016). A Bibliometric Study of the scientific publications on patient-reported outcomes in Rheumatology. Semin Arthritis Rheum, 46(6):828-833.

41. Salado-Font SM, López-Muñoz F, Povedano-Montero FJ, Labella Quesada F. (2017). Análisis bibliométrico de la producción científica sobre el efecto del consumo de estatinas en las manifestaciones oftalmológicas de la miastenia gravis. Arch Soc Esp Oftalmol, 92(10):464-471.

42. Povedano-Montero FJ, Alvarez-Peregrina C, Hidalgo Santa Cruz F, Villa-Collar C, Sanchez Valverde J. (2018). Bibliometric Study of Scientific Research on Scleral Lenses. Eye Contact Lens, 44 Suppl 2:S285-S291.

43. López-Muñoz F, Povedano-Montero FJ, Chee KY, et al. (2018). A bibliometric analysis of scientific production on secondgeneration anti-psychotic drugs in Malaysia. Malays J Med Sci, 25(3):40-55.

44. Villa-Collar C, Alvarez-Peregrina C, Hidalgo Santa Cruz F, Povedano-Montero FJ. (2018). Bibliometric Study of Scientific Research on Overnight Orthokeratology. Eye Contact Lens, 44(5):344-349.

45. Falagas ME, Pitsouni EI, Malietzis GA, Pappas G. (2008). Comparison of PubMed, Scopus, Web of Science, and Google Scholar: strengths and weaknesses. Faseb j, 22(2):338-342.

46. Kulkarni AV, Aziz B, Shams I, Busse JW. (2009). Comparisons of citations in Web of Science, Scopus, and Google Scholar for articles published in general medical journals. Jama, 302(10):1092-1096.
Egghe 1, Ravichandra Rao IK. (1992). Classification of growth models based on growth rates and its applications. Scientometrics, 25(1):5-46.

48. Bradford SC. (1934). Sources of informations on specific subjects. J Inf Sci, 137:85-86.

49. Garfield E. (1979). Citation indexing. Its theory and application in science, technology and humanities. New York: John Wiley \& Sons.

50. Lotka AJ. (1926). The frecuency distribution of scientific productivity. J Wash Acad Sci, 12(16):317-323.

51. Pérez Andrés C, Estrada Lorenzo JM, Villar Álvarez F, Rebollo Rodríguez MJ. (2002). Estudio bibliométrico de los artículos originales de la Revista Española de Salud Pública (1991-2000). Parte primera: Indicadores Generales. Rev Esp Salud Public, 76(6):659-672.

52. Povedano-Montero FJ, Alvarez-Peregrina C, Hidalgo Santa Cruz F, Villa-Collar C, Sanchez Valverde J. (2018). Bibliometric Study of Scientific Research on Scleral Lenses. Eye Contact Lens, 44 Suppl 2:S285-s291.

53. López Piñero JM, Terrada ML. (1992). Los indicadores bibliométricos y la evaluación de la actividad médico-científica. IV. La aplicación de los indicadores. Med Clin-Barcelona, 98(10):384-388.

54. King J. (1987). A review of bibliometric and other science indicator and their role in research evaluation. J Inf Sci, 13(5):261276.

55. Nigel Gilbert G. (1978). Measuring the growth of science. A review of indicators of scientific growth. Scientometrics, 1(1):934.

56. JD M, AB J-G, F L-M, F C. (2012). Evolution of the Concept of Treatment-resistant Schizophrenia: Toward a Reformulation for Lack of an Adequate Response - ScienceDirect. J Exp Clin Med, 4:98-102.

57. Alexander TH, Harris JP. (2013). Incidence of sudden sensorineural hearing loss. Otol Neurotol, 34(9):1586-1589.

58. Kim SH, Kim SJ, Im H, Kim TH, Song JJ, Chae SW. (2017). A Trend in Sudden Sensorineural Hearing Loss: Data from a Population-Based Study. Audiol Neurootol, 22(6):311-316.

59. Edizer DT, Celebi O, Hamit B, Baki A, Yigit O. (2015). Recovery of Idiopathic Sudden Sensorineural Hearing Loss. J Int Adv Otol, 11(2):122-126.

60. Ermutlu G, Suslu N, Yilmaz T, Sarac S. (2017). Sudden hearing loss: an effectivity comparison of intratympanic and systemic steroid treatments. Eur Arch Otorhinolaryngol, 274(10):35853591.

61. Olex-Zarychta D. (2017). Successful treatment of sudden sensorineural hearing loss by means of pharmacotherapy combined with early hyperbaric oxygen therapy: Case report. Medicine (Baltimore), 96(51):e9397.

62. Eryigit B, Ziylan F, Yaz F, Thomeer H. (2018). The effectiveness of hyperbaric oxygen in patients with idiopathic sudden sensorineural hearing loss: a systematic review. Eur Arch Otorhinolaryngol, 275:2893-2904. 
63. Ashtiani MK, Firouzi F, Bastaninejad S, et al. (2018). Efficacy of systemic and intratympanic corticosteroid combination therapy versus intratympanic or systemic therapy in patients with idiopathic sudden sensorineural hearing loss: a randomized controlled trial. Eur Arch Otorhinolaryngol, 275(1):89-97.
Tsounis M, Psillas G, Tsalighopoulos M, Vital V, Maroudias N. (2018). Systemic, intratympanic and combined administration of steroids for sudden hearing loss. A prospective randomized multicenter trial. Eur Arch Otorhinolaryngol, 275(1):103-110.

64.

Ready to submit your research? Choose Auctores and benefit from:

* fast, convenient online submission

* rigorous peer review by experienced research in your field

* rapid publication on acceptance

* authors retain copyrights

* unique DOI for allarticles

* immediate, unrestricted online access

At Auctores, research is always in progress.

Learn more www.auctoresonline.org/journals/journal-of-clinicalotorhinolaryngology

DOI: $10.31579 /$ tohns.2020/002 